\title{
Cultivating College Students' Self-Leadership: The Dual Role of Family and School
}

\author{
Yang Wen, Liu Baowei, Zhang $\mathrm{Li}^{*}$ \\ School of Management, Harbin Institute of Technology, Harbin, China \\ Email address: \\ yang1720101@foxmail.com (Zhang Li) \\ ${ }^{*}$ Corresponding author
}

To cite this article:

Yang Wen, Liu Baowei, Zhang Li. Cultivating College Students' Self-Leadership: The Dual Role of Family and School. Psychology and Behavioral Sciences. Vol. 9, No. 2, 2020, pp. 17-23. doi: 10.11648/j.pbs.20200902.13

Received: April 7, 2020; Accepted: May 12, 2020; Published: May 27, 2020

\begin{abstract}
Intrinsic control and self-management are playing an increasingly indispensable role in personal development. In the meantime, as the core of inner influence, self-leadership tends to be more prominent in the procedure of self-management. And in the process of students' growth, home education and school education are two complementary and critical nurturing roles. The key point of this paper is whether the students' self-leadership level could be effectively improved through the specific guidance of family and school. Therefore, on the basis of the existing theories, this paper firstly reviews the self-leadership theory in the past three decades, together with its research content. Then this paper analyses the components of self-leadership strategy as well as its shaping effect on behaviors and thought. It is generally accepted that the self-leadership strategy could be divided into three main dimensions which are behavior-focused, natural reward and constructive thought pattern strategies. Finally, this study explores the antecedent influence of parenting styles and leadership education on college students' self-leadership level from a novel perspective via the revised Chinese version of RSLQ and the revised Chinese version of EMBU. Through empirical research and detailed data analysis, this study successfully verifies the dual role of family and school in self-leadership cultivation.
\end{abstract}

Keywords: Self-Leadership, Parenting Styles, Leadership Education, Intrinsic Control

\section{Introduction}

Under the requirement of the new higher education development plan, the cultivation of college students' leadership has become the focus point, which is of great significance to the comprehensive development of high-quality talents and compound innovative talents. In addition to effective leadership at the organizational level, leadership at the ego level is playing a fundamental role that cannot be ignored. Manz proposed that self-leadership is based on the self-adjustment, self-control, self-management and social cognitive theory, using the natural reward, constructive thought in order to obtain a series of individual internal behavior strategy [1], which is a process in which individuals control their own behaviors, influence and guide themselves by specific behavioral and cognitive strategies [2] Through abundant psychological theories, self-leadership expounds the process affecting individual performance [3]. Sufficient studies have shown that self-leadership can improve the level of individual task completion through the influence on self-goal setting [4], the self-regulation of individual emotions [5], and the stimulation of individual creativity and innovation ability [6].

It is not difficult to find that the concept of self-leadership emphasizes the normative process of self-influence, and this mode of action is also a challenge to traditional leadership behaviors -- generally speaking, it is commonly accepted that leadership requires at least one leader and one follower [7], and the generation of leadership behaviors is also regarded as an interactive process [8]. Self-leadership is different. It shows that a person can play both roles in the course of behavior. Under the requirement of such conflict-type role, the significance of college students' self-leadership cultivation should not be ignored.

\subsection{Self-Leadership Theory}


Inspired by Kerr and Jermier (1978) 'alternatives to leadership' [9], the self-leadership theory proposed by American scholar Manz in the 1980s was originally evolved from the concept of self-management [10], rooted in the social cognitive theory that integrates relevant concepts of self-control, and was also the combination product of the self-management with social learning theory and behavior modification theory [10-12]. Self-management is the process in which individuals actively apply behaviors and cognitive self-influence strategies to manage their own thoughts, emotions, behaviors, and situation [13, 14]. And the self-leadership theory which is developed on the basis of the concept above is defined by Manz as a comprehensive perspective of self-influence, including guiding yourself to complete the tasks of natural motivation and those must be done but not natural incentives work [15].

Moreover, according to Manz, the key to self-leadership is control. The process of self-leadership begins with comparing the perceived current state with self-setting standards, perceiving and evaluating the gap, and then adjust their behavior to narrow the gap and form a new objective state, which is a circulation of the self-leadership process -- external demand should be brought into the personal thoughts and behavior choice and take action [7]. External demand has the objectivity, so the final individual behavior strategy is only the result of self-influence which is a process of internalization.

\subsection{Self-Leadership Strategy}

In the past 30 years, the theory of self-leadership has been developing and attracting more and more attention from the academic community. Self-leadership, which is built on self-management, puts more emphasis on cognition, internal reward, other internal factors and some factors beyond behavior [16]. Self-leadership theory aims to use specific behavior and cognitive strategies to improve self-consciousness and actively guide the optimization improvement of individual performance [2]. According to existing studies, scholars usually divide self-leadership strategies into three categories: behavior-focused strategies, natural reward strategies and constructive thought pattern strategies [17]. On this basis, the study further development towards the direction of the quantitative analysis. Scholars have developed a series of items and the scale for individual self-leadership measurement, among these the most widely accepted is RSLQ [18] established by Houghton and Neck. RSLQ is based on the version developed by Anderson and Prussia in 1997, divided these 50 items of the three categories of self-leadership strategies into 9 dimensions and 35 items.

\subsubsection{Behavior-Focused Strategies}

The behavior-focused strategies aim to build an introspective framework that promotes self-awareness and behavior management, including self-observation, self-goal setting, self-reward, self-punishment, and self-cueing. The following only elaborates on the relevant dimensions of the revised Chinese version of RSLQ.

Self-goal setting, a theory proposed by Locke, believes that challenging goals can effectively serve as an incentive [20]. And goal setting is the most direct driving force for self-efficacy improvement and behavior change. It can transform people's needs into motivation, and then guide individuals to work towards goals [21], which can significantly improve individual performance [22].

Self-reward, a way for individuals to provide support and motivation for expected behavior and goal realization [23], can promote individual pursuit of goals [24]. The reward can be an intangible spiritual motivation or a more tangible material motivation.

Self-punishment can serve as a positive individual lead when it can successfully establish a positive behavior correction framework, but excessive self-criticism or habitual confession is usually mixed to negative support [25].

\subsubsection{Natural Reward Strategies}

The natural reward strategies aim to create an active and positive mood to face and complete the task, and the individual will be motivated by some characteristics inherent in the task [26]. This strategy comes in two flavors, with natural rewards embedded -- adding pleasant or satisfying features to the task; Focus on natural rewards -- pay more attention to the pleasurable or satisfying aspects [27]. Both of these approaches are from the perspective of intrinsic motivation [28]. Studies have proved that they can effectively improve the understanding of tasks [29] and satisfaction [30], thus leading to the improvement of performance [31]. Moreover, people who are good at using natural reward strategies are more likely to become self-leaders [32].

\subsubsection{Constructive Thought Pattern Strategies}

Constructive thought pattern strategies are to cultivate and promote the formation of constructive thought mode [33], so as to improve the degree of self-leading. In the following, it will analyze self-talk and visualizing successful performance which are its subdivisions.

Self-talk is simply described as an individual 's psychological self-communication. Theodoraki defines it as a cognitive activity in which an individual talks with himself aloud or whispered in his mind [34], which is a dynamic and multidimensional guidance and incentive functional conversation, which plays an important role in shaping individual cognition, behavior, and thinking [35].

Anticipating successful performance is also a kind of mental image, which is to foresee the task before it is executed-that is, hidden cognitive creation. The meta-analysis conducted by Driskell et al. found that this psychological prediction can significantly improve individual performance [36]. And it was also proved that people who could predict success were generally superior in the performance of actual tasks [2].

\subsection{Research Significance}

It has been more than 30 years since the emergence of self-leadership. Although there has been a relatively perfect development and progress in terms of concept definition, 
theoretical support, quantitative evaluation, and research on outcome variables, there are few empirical studies on its antecedent variables in existing papers. Most of past studies still focus on the following angles: self-leadership measurement in theoretical level, individual behavior guidance and organizational management improvement in practical level, while ignoring the cultivation of self-leadership. In addition, the existing researches always pay more attention to the enterprise employees than the students, especially undergraduates.

The more a person tends to self-lead, the less dependent the individual's behavior is on external motivation. Therefore, it can be said that self-leadership captures the highest level of intrinsic control in an organization [37]. When external environmental factors are uncontrollable, the central role of self-leadership in shaping behavior will be more prominent. However, even if the external environment has an impact on the performance of individuals in the organization, whether or not the behavior changes and the degree of change are the results of individual's choice. Essentially, in the process of behavior control, self-leadership is self-imposed, and it is also an element that really plays a central role in this process [7]. Therefore, for college students, the cultivation of self-leadership is not only in line with current education policies, but also an inevitable requirement for individual development. With a more inclusive and broader perspective, self-leadership expounds a self-management process based on individual behavior and consciousness, including attention to intrinsic motivation and cognition [38], which is a continuous structure free from external forces. No matter from the individual level or the organizational level, this continuous control structure constructed by self-leadership has brought about the shaping of behaviors and standards in the process of task execution. Education, as the most intuitive cultivation method, has always played a role that cannot be neglected in the development of personal abilities. Especially in recent years, the promotion and popularization of comprehensive quality education systems such as leadership courses have made this role particularly prominent. Therefore, this study views leadership curriculum education as an important factor affecting college students' self-leadership. (Figure 1- $\mathrm{H}_{2}$ )

In the background of students 'growth, family factors play an important role. In the family, parents who are the first teachers have a profound influence on the students. Parenting style refers to the educational concept, attitude towards children and all words and behaviors in the process of parenting held by parents during their education and rearing of children [39]. This behavior research perspective is also an important topic concerned in the cultivation of individual psychology, ability and other traits [40]. Parental parenting behaviors include both specific behaviors of parents performing their duties under the guidance of target orientation, as well as non-target-oriented parenting behaviors such as changes in posture, gestures, intonation, or spontaneous expression of emotions [39]. A large number of existing studies have fully demonstrated that parenting style is significantly correlated with many aspects of individual ability cultivation, such as self-concept [41] and individual achievement motivation influenced by it [42]. As a core component of the individual's cognitive system, self-concept is an individual's perception and evaluation of self-existence under the guidance of experience and external feedback [43], and the positive parenting style is conducive to the formation of high self-concept [44]. In addition, studies have also confirmed that parenting style can affect individuals' self-efficacy and behavioral goal orientation [45]. Inspired by the above conclusions, this study makes the hypothesis that parenting style plays antecedent role in the cultivation of self-leadership. (Figure 1- $\mathrm{H}_{1}$ )

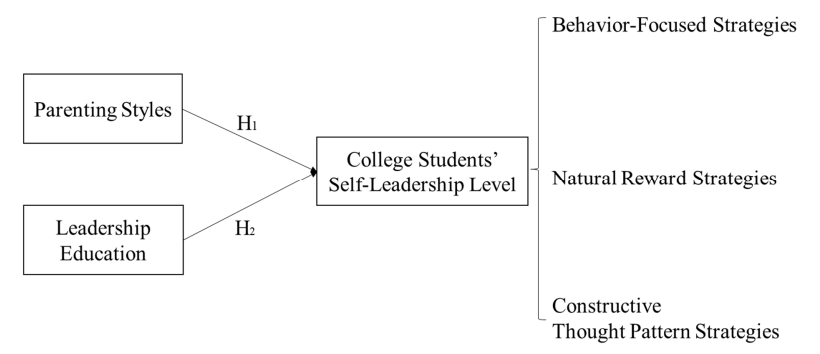

Figure 1. Research model.

\section{Method}

\subsection{Participants}

In this study, through a two-stage questionnaire survey, the undergraduates in the leadership and communication course of Harbin Institute of Technology were taken as the research object to explore the antecedent variables of self-leadership. The first phase of the study focused on the influence of parental rearing on self-leadership cultivation. The questionnaire was based on the Chinese version of RSLQ designed by Neubert and $\mathrm{Wu}$ (2006) and the Chinese version of EMBU [46] revised by Yue Dongmei et al. In the second stage, on the basis of the previous data research, the results of the two self-leadership measurements were compared and analyzed to explore the role of leadership curriculum education on self-leadership cultivation. In the first stage, 183 questionnaires were collected, among which 177 were valid. In the second stage, a total of 176 questionnaires were collected and 176 valid questionnaires were collected.

\subsection{Materials}

\subsubsection{Self-Leadership Scale}

The self-leadership table used in this article is the Chinese version of RSLQ [19] designed by Neubert and Wu (2006). On the basis of the original RSLQ version, dimensions and items with insignificant correlation are eliminated, and the remaining 6 dimensions and 25 items (Figure 2), the six dimensions are self-goal setting, self-reward, self-punishment, focusing thoughts on natural rewards, visualizing successful performance and self-talk. 


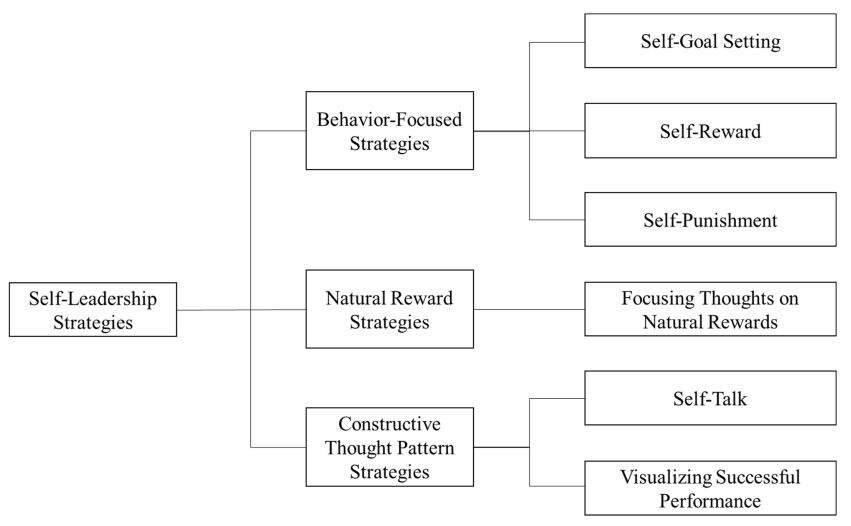

Figure 2. $R S L Q$ Chinese version.

\subsubsection{Parenting Styles Scale}

This paper adopts a revised Chinese version of EMBU by Yue Dongmei et al., and selects one dimension, the overprotection dimension, which contains eight problems after revision and has been tested for reliability in the existing studies. On the one hand, it conforms to the purpose of the research, and on the other hand, it can control the length of the full text of the questionnaire to ensure the validity of the questionnaire.

\subsubsection{Measurement of the Role of Leadership Education}

This study aims to explore the antecedent variables of self-leadership by issuing two-stage questionnaires at the beginning and end of the course. In addition to the above two scales, the role of leadership curriculum education in the cultivation of college students' self-leadership was explored by comparing and analyzing the data results of two times.

\section{Findings}

The questionnaire included questions relating to each dimension of each variable. The answers were on a scale of 1-6. $1=$ Very high to $6=$ Very low.

Table 1, 2, 3 shows the codes and descriptive statistical results of all variables mentioned by the model. The following data have passed the reliability and validity tests.

Table 1. The code of the research variables.

\begin{tabular}{ll}
\hline Description & Variable code \\
\hline Visualizing Successful Performance & VSP1/2 \\
Self-goal Setting & SGS1/2 \\
Self-talk & ST1/2 \\
Self-reward & SR $1 / 2$ \\
Self-punishment & SP1/2 \\
Focusing Thoughts on Natural Rewards & FTONR $1 / 2$ \\
Parenting Styles & PS $1 / 2$ \\
\hline
\end{tabular}

Table 2. Descriptive statistics of the research variables in stage one.

\begin{tabular}{llllll}
\hline & N & Minimum & Maximum & Mean & Std. Deviation \\
\hline VSP1 & 177 & 1.00 & 5.00 & 2.3424 & .70683 \\
SGS1 & 177 & 1.00 & 5.40 & 2.4362 & .73302 \\
ST1 & 177 & 1.00 & 6.00 & 2.7797 & 1.26523 \\
SR1 & 177 & 1.00 & 6.00 & 2.2712 & .99203 \\
SP1 & 177 & 1.00 & 5.75 & 2.7542 & .81815 \\
FTONR1 & 177 & 1.00 & 5.00 & 2.5164 & .65904 \\
PS & 177 & 1.00 & 5.11 & 3.5316 & .69624 \\
Valid N & 177 & & & & \\
(listwise) & & & & & \\
\hline
\end{tabular}

Table 3. Descriptive statistics of the research variables in stage two.

\begin{tabular}{llllll}
\hline & $\mathbf{N}$ & Minimum & Maximum & Mean & Std. Deviation \\
\hline VSP2 & 176 & 1.00 & 4.00 & 2.0773 & .69311 \\
SGS2 & 176 & 1.00 & 3.80 & 2.1114 & .65647 \\
ST2 & 176 & 1.00 & 6.00 & 2.5265 & 1.16152 \\
SR2 & 176 & 1.00 & 5.00 & 2.0492 & .88950 \\
SP2 & 176 & 1.00 & 5.50 & 2.7017 & .93454 \\
FTONR2 & 176 & 1.00 & 4.40 & 2.2511 & .69307 \\
Valid N & 176 & & & & \\
(listwise) & 176 & & & \\
\hline
\end{tabular}

\subsection{The Antecedent Effect of Parenting Style on College Students' Self-Leadership}

To verify hypothesis 1, Pearson Correlation coefficient was used to test the Correlation between parenting style and self-leadership level, and the results showed that the correlation was significant (Pearson Correlation $=0.502$, Sig $<0.01$ ), indicating that hypothesis 1 , parenting style can play a certain antecedent effect in college students' self-leadership cultivation.

Table 4. Pearson Correlation Coefficient.

\begin{tabular}{llll}
\hline & PS & SL1 & \\
\hline PS & Pearson Correlation & 1 & $.502^{* *}$ \\
& Sig. (2-tailed) & & .000 \\
SL1 & Pearson Correlation & $.502 * *$ & 1 \\
& Sig. (2-tailed) & .000 & \\
\hline
\end{tabular}

\subsection{The Antecedent Effect of Leadership Education on College Students' Self-Leadership}

To test Hypothesis 2, a paired sample T-test was used to test the antecedent effect of leadership education on the self-leadership cultivation of college students $(\mathrm{t}=3.648$, Sig $<0.01)$. It can be considered that the leadership education has caused differences in the level of self-leadership.

Table 5. Paired samples test of the whole scale.

\begin{tabular}{llllllll}
\hline & Std. Deviation & Std. Error Mean & \multicolumn{2}{l}{$\mathbf{9 5 \%}$ Confidence Interval of the Difference } & \multicolumn{3}{l}{ Sig. (2-tailed) } \\
\hline & & Lower & Upper & & \\
Pair 1 & SL1 - SL2 & .84020 & .06333 & .10607 & .35605 & 3.648 & 175 \\
\hline
\end{tabular}

By dividing hypothesis 2 into six dimensions of self-leadership and conducting paired sample t-test, the results showed that visualizing successful performance, self-goal setting and focusing on thinking on Natural Rewards had the most significant changes before and after the leadership course. It shows that education has the most 
profound influence in these three aspects, while it does not self-reward and self-punishment. play a prominent role in the dimensions of self-talk,

Table 6. Paired samples test of the dimensions.

\begin{tabular}{|c|c|c|c|c|c|c|c|c|}
\hline \multirow[b]{2}{*}{ Pair 1} & \multirow{2}{*}{$\begin{array}{l}\text { Std. Deviation } \\
\text { VSP1/2 }\end{array}$} & \multirow{2}{*}{$\begin{array}{l}\text { Std. Error Mean } \\
1.05825\end{array}$} & \multicolumn{3}{|c|}{ 95\% Confidence Interval of the Difference } & \multicolumn{3}{|c|}{ Sig. (2-tailed) } \\
\hline & & & .07977 & .11075 & .42561 & 3.362 & 175 & .001 \\
\hline Pair 2 & $\mathrm{SGS} 1 / 2$ & 1.06468 & .08025 & .16661 & .48339 & 4.050 & 175 & .000 \\
\hline Pair 3 & $\mathrm{ST} 1 / 2$ & 1.66294 & .12535 & .00829 & .50307 & 2.040 & 175 & .043 \\
\hline Pair 4 & $\mathrm{SR} 1 / 2$ & 1.33124 & .10035 & .02355 & .41964 & 2.208 & 175 & .029 \\
\hline Pair 5 & $\mathrm{SP} 1 / 2$ & 1.30939 & .09870 & -.14366 & .24593 & .518 & 175 & .605 \\
\hline Pair 6 & FTONR1/2 & 1.00496 & .07575 & .11527 & .41428 & 3.495 & 175 & .001 \\
\hline
\end{tabular}

\section{Conclusion}

Different from previous studies, this study focuses on the cultivation of college students' self-leadership and the exploration of its antecedent variables. It is the first time to combine the parenting style with the development of self-leadership, and to illustrate the antecedent role of receiving leadership education by examining the difference of students' self-leadership at the beginning and end of the course.

\subsection{Theoretical and Practical Significance}

Both the two hypotheses in this research model has been verified effectively. Students who adopt positive parenting style show a higher level of self-leadership. During their growth, their parents usually do not overprotect and interfere with their behaviors and decisions, and give them more autonomy [47]. On the one hand, it is beneficial to cultivate students' ability of self-management in behavior, on the other hand, it can also cultivate students' thinking mode of self-leadership. Although the antecedent role of parenting styles in shaping many individual abilities has been confirmed, it is the first time that this perspective has been put on the level of self-leadership. Therefore, this study further confirms that reducing excessive parental protection and intervention is helpful for the cultivation and development of students' self-leadership, and provides a new dimension worth exploring for the study of antecedent variables of self-leadership.

As an important part of the university education system in recent years, the leadership curriculum has played a vital role in the cultivation of potential career. As a key evaluation standard for the newly-emerged comprehensive ability that has received much attention, whether self-leadership can be effectively improved through leadership courses is another hypothesis explored in this paper. After receiving the course of leadership education, students' self-leadership level has been improved compared with that before the course, which indicates that the course of leadership education can play a significant role in the process of self-leadership cultivation. Education, as a social practice that has the most profound influence on students' physical and mental development, still performs well in the cultivation of self-leadership. The role of education in different dimensions of self-leadership is also different. Therefore, in this sense, this study also provides new ideas and references for the reform and development of leadership education in the future -- for example, combining educational purposes with educational methods in a targeted way, and specifically investigating the mechanism of teaching methods in improving students' specific ability.

\subsection{Limitations of Research}

The positive parenting styles explored in the study have a slightly broader effect on the cultivation of college students' self-leadership, and they have not been detailed to specific parenting behaviors. In addition, this study is limited by the duration of the course and the coverage of grades, so it has not been possible to explore the level of student self-leadership for a long time. The influence of education is a far-reaching and lasting process, which is more meaningful in the change of long-term behavior pattern. However, this time, only the effect of short-term improvement has been considered. If there is an opportunity, long-term follow-up investigation should be conducted to explore the significance of leadership education for self-leadership cultivation.

\section{Result}

The research has confirmed that positive parenting style has a significant promoting effect on the cultivation of college students' self-leadership, and the curriculum education of leadership is beneficial to the cultivation of college students' self-leadership, especially on the three dimensions of visualizing successful performance, self-goal setting and focusing on thoughts on natural rewards.

\section{References}

[1] Manz, C. C., "Self-leadership: toward an expanded theory of self-influence processes in organizations," Academy of Management Review, 1986, Vol. 11, pp. 585-600.

[2] Manz, C. C. and Neck, C. P., "Mastering self-leadership: Empowering yourself for personal excellence," 3rd ed., Pearson Prentice-Hall, Upper Saddle River, 2004, NJ.

[3] Neubert M J, and Wu J C C. "An investigation of the generalizability of the Houghton and Neck revised self -leadership questionnaire to a Chinese context," Journal of Managerial Psychology, 2006, Vol. 21, pp. 360-373.

[4] Christopher P. Neck, Hossein Nouri, and Jeffrey L. Godwin. "How self-leadership affects the goal-setting process," Human Resource Management Review, 2003, Vol. 13. 
[5] Stewart G L, Courtright S H, and Manz C C. "Self-leadership: A multilevel review. Journal of Management," 2011, Vol. 37, pp. 185-222.

[6] Ghosh, and Koustab. "Developing organizational creativity and innovation,” Management Research Review, 2015, Vol. 38, pp. 1126-1148.

[7] Greg L. Stewart, Stephen H. Courtright, and Charles C. Manz. "Self-leadership: A paradoxical core of organizational behavior," Annual Review of Organizational Psychology and Organizational Behavior, 2019, Vol. 6, pp. 47-67.

[8] De Rue DS, and Ashford SJ. "Who will lead and who will follow? A social process of leadership identity construction in organizations,” Acad. Manag. Rev, 2010, Vol. 35, pp. 627-47.

[9] Kerr, S. and Jermier, J. M., "Substitutes for leadership: Their meaning and measurement," Organization Behavior and Human Performance, 1978, Vol. 22, pp. 375-403.

[10] Manz, C. C. and Sims, H. P. Jr, "Self-management as a substitute for leadership: A social learning perspective," Academy of Management Review, 1980, Vol. 5, pp. 361-7.

[11] Bandura A. "Social foundations of thought and action: A social cognitive theory," Englewood Cliffs, 1986, NJ: Prentice-Hall.

[12] Luthans F, and Kreitner R. "Organizational behavioral modification and beyond," Glenview, 1985, IL: Scott Foresman.

[13] Schunk D H, and Zimmerman B J. "Social origins of self-regulatory competence," Educational Psychologist, 1997, Vol. 32, pp. 195.

[14] Andrasik F, and Heimberg JS. "Self-management procedures," In Handbook of Organizational Behavior Management, ed. LW Frederickson, 1982, pp. 219-47. New York: Wiley.

[15] Manz, C. C. "The art of self-leadership: Strategies for personal effectiveness in your life and work," Upper Saddle River, 1983, NJ: Prentice Hall.

[16] Neck C P, Manz, C. C., and Houghton JD. "Self-leadership: The definitive guide to personal excellence," Thousand Oaks, 2017, CA: Sage.

[17] Anderson J S, and Prussia G E. "The self-leadership questionnaire: Preliminary assessment of construct validity," Journal of Leadership \& Organizational Studies, 1997, Vol. 4, pp. 119-143.

[18] Houghton J D, and Neck C P. "The revised self-leadership questionnaire: Testing a hierarchical factor structure for self-leadership," Journal of Managerial Psychology, 2002, Vol. 17, pp. 672-691.

[19] Neubert M J, and Cindy Wu J C. "An investigation of the generalizability of the Houghton and Neck Revised Self-Leadership Questionnaire to a Chinese context," Journal of Managerial Psychology, 2006, Vol. 21, pp. 360-373.

[20] Locke, E. A. and Latham, G. P., "A theory of goal setting and task performance," Prentice-Hall, Englewood Cliffs, 1990, NJ.

[21] Locke Edwin, Schweiger David, and Latham Gary. "Participation in decision making: When should it be used?" Organizational Dynamics, 1986, Vol. 14, pp. 65-79.

[22] Locke Edwin, and Schippers Michaéla. "Improving lives: personal goal setting boosts student performance and happiness," Academy of Management Proceedings, 2018, 16790. 10.5465/AMBPP.2018.16790symposium.

[23] Mahoney MJ, and Arnkoff DB. "Self-management: Theory, research, and application," In Behavioral Medicine: Theory and Practice, ed. JP Brady, D Pomerleau, 1979, pp. 75-96. Baltimore: Williams and Wilkins.

[24] Neck C P, and Manz C C. "Mastering self-leadership: Empowering yourself for personal excellence," Pearson, 2010.

[25] Inbar Yoel, Pizarro David, Gilovich Thomas, and Ariely, Dan. "Moral masochism: On the connection between guilt and self-punishment," Emotion (Washington, D. C.). 2012, 13. 10.1037/a0029749.

[26] Manz C C, and Sims H P. "The new super leadership: Leading others to lead themselves," Berrett-Koehler, 2001.

[27] Houghton J D, Neck C P, and Manz C C. "We think we can, we think we can, we think we can: The impact of thinking patterns and self-efficacy on work team sustainability," Team Performance Management: An International Journal, 2003, Vol 9, pp. 31-41.

[28] Deci, E. and Ryan, R. "The support of autonomy and control of behavior," Journal of Personality and Social Psychology, 1985, Vol. 53, pp. 1024-37.

[29] Ilgen D R, and Hollenbeck J R. "The structure of work: Job design and roles," Handbook of Industrial and Organizational Psychology, 1991, Vol. 2, pp. 165-207.

[30] Long C S, Alifiah M N, Kowang T O, and Ching C W. "The relationship between self-leadership, personality and job satisfaction: A review," Journal of Sustainable Development, 2015, Vol. 8, pp. 16.

[31] Seibert S E, Crant J M, and Kraimer M L. "Proactive personality and career success," Journal of Applied Psychology, 1999, Vol. 84, pp. 416

[32] Neck CP, and Manz CC. "Thought self-leadership: The impact of mental strategies training on employee cognition, behavior, and affect," Journal of Organizational Behavior, 1996, Vol. 17, pp. 445-67.

[33] Neck, C. P. and Manz, C. C. "Thought self-leadership: The impact of self-talk and mental imagery on performance", Journal of Organizational Behavior, 1992, Vol. 12, pp. 681-99.

[34] Theodorakis Y, Chroni S, Laparidis K, Bebetsos V, and Douma I. "Self-talk in a basketball. shooting task," Perceptual and Motor Skills, 2001, Vol. 92, pp. 309-15.

[35] Senay I, Albarracin D, and Noguchi K. "Motivating goal-directed behavior through introspective self-talk: The role of the interrogative form of simple future tense," Psychological Science, 2010, Vol. 21, pp. 499-504.

[36] Driskell, J. E., Copper, C. and Moran, A. "Does mental practice enhance performance?" Journal of Applied Psychology, 1994, Vol. 79, pp. 481-92.

[37] Manz CC. "Taking the self-leadership high road: Smooth surface or potholes ahead?" Acad. Manag. Perspect. 2015, Vol. 29 , pp. 132-51.

[38] Manz, C. C. "Leading employees to be self-managing and beyond: Toward the establishment of self-leadership in organizations," Journal of Management Systems, 1991, Vol. 3, pp. 15-24. 
[39] Nancy Darling, and Laurence Steinberg. "Parenting style as context: An integrative model," Psychological Bulletin, 1993, Vol. 113.

[40] Perris C, Jacobsson L, Lindström H, Von Knorring Lars, and Perris, H. "Development of a new inventory assessing memories of parental rearing behaviour." Acta Psychiatrica Scandinavica, 1980, Vol. 61, pp. 265-74.

[41] Misukanis, T. M., Bun, J. R., Mueller, R. A., and Louiselle, P. A., "Effects of parental authoritarianism and authoritativeness on self-esteem," Personality and Social Psychology Bulletin, 1988, Vol. 14, pp. 271-282.

[42] Nicholls, J. G. "Achievement motivation: Conceptions of ability, subjective experience, task choice and performance," Psychological Review, 1984, Vol. 121, pp. 345-374.

[43] Shavelson, R. J., Hubner, J. J., and Stanton, G. C. "Self-concept: Validation of construct interpretations," Review of Educational Research, 1976, Vol. 46, pp. 407-441.
[44] Jones, M. H., Audley-Piotrowski, S. R., and Kiefer, S. M. "Relationships among adolescents' perceptions of friends' behaviors, academic self-concept, and math performance," Journal of Educational Psychology, 2012, Vol. 104, pp. 19.

[45] Prabhu, V., Sutton, C., and Sauser, W. "Creativity and certain personality traits: Understanding the mediating effect of intrinsic motivation," Creativity Research Journal, 2008, Vol. 20, pp. 53-66.

[46] Ross Michael, Campbell R, Clayer J. "New inventory for measurement of parental rearing patterns: An English form of the EMBU," Acta Psychiatrica Scandinavica, 1983, Vol. 66, pp. 499-507.

[47] Tak Wing Chan, Anita Koo. "Parenting style and youth outcomes in the UK," European Sociological Review, 2011, Vol. 3. 